\title{
Welcome Associate Editor John Windsor
}

\section{John G. Hunter}

(C) Société Internationale de Chirurgie 2010

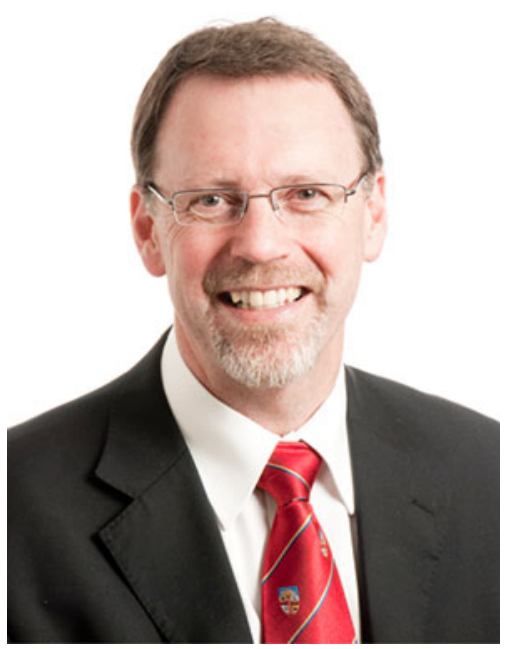

The World Journal of Surgery welcomes John Windsor to our associate editor ranks. Professor Windsor's expertise spans pancreatobiliary surgery, upper GI tract surgery, surgical education, international surgery, and the interface of engineering, technology, and surgery. While maintaining a distinct specialty interest, Professor Windsor is truly a general surgeon, a most noble-if vanishing-breed.
Professor Windsor is the Head of the Department of Surgery at the University of Auckland, New Zealand, and holds a personal chair of surgery in that department.

Professor Windsor was raised in India and New Zealand, attended the University of Otago, in Dunedin, NZ, and completed his medical training at the University of Auckland. Following a research doctorate in malnutrition and surgical metabolism under Graham Hill in Auckland, Professor Windsor completed his training in HPB and upper GI tract surgery under David Carter in Edinburgh. He returned to New Zealand in 1991 and quickly "rose through the ranks," assuming the Head of the Department role in 2004. Along the way he has won prestigious awards for his innovative research and for his excellence in education. His skill in open and laparoscopic surgery has been rewarded with a busy practice in pancreatobiliary and upper GI tract surgery. Professor Windsor has served on the editorial board of the WJS for the last four years and currently serves as Secretary of the International HPB Association. The World Journal of Surgery will be much the stronger for the addition of the talented John Windsor to our superb team of associate editors. Many thanks, and welcome aboard!
J. G. Hunter $(\bowtie)$

Department of Surgery, School of Medicine, Oregon Health Sciences University, 3181 SW Sam Jackson Road, Portland, OR 97239, USA

e-mail: hunterj@ohsu.edu 